This item was submitted to Loughborough's Research Repository by the author.

Items in Figshare are protected by copyright, with all rights reserved, unless otherwise indicated.

\title{
Key influences of innovation magnitude and mode
}

PLEASE CITE THE PUBLISHED VERSION

http://dx.doi.org/10.1680/mpal.2010.163.4.161

PUBLISHER

(C) ICE Publishing

VERSION

VoR (Version of Record)

LICENCE

CC BY-NC-ND 4.0

REPOSITORY RECORD

Shaw, Nicholas, Dino Bouchlaghem, and Peter Demian. 2019. "Key Influences of Innovation Magnitude and Mode". figshare. https://hdl.handle.net/2134/14638. 
This item was submitted to Loughborough's Institutional Repository (https://dspace.lboro.ac.uk/) by the author and is made available under the following Creative Commons Licence conditions.

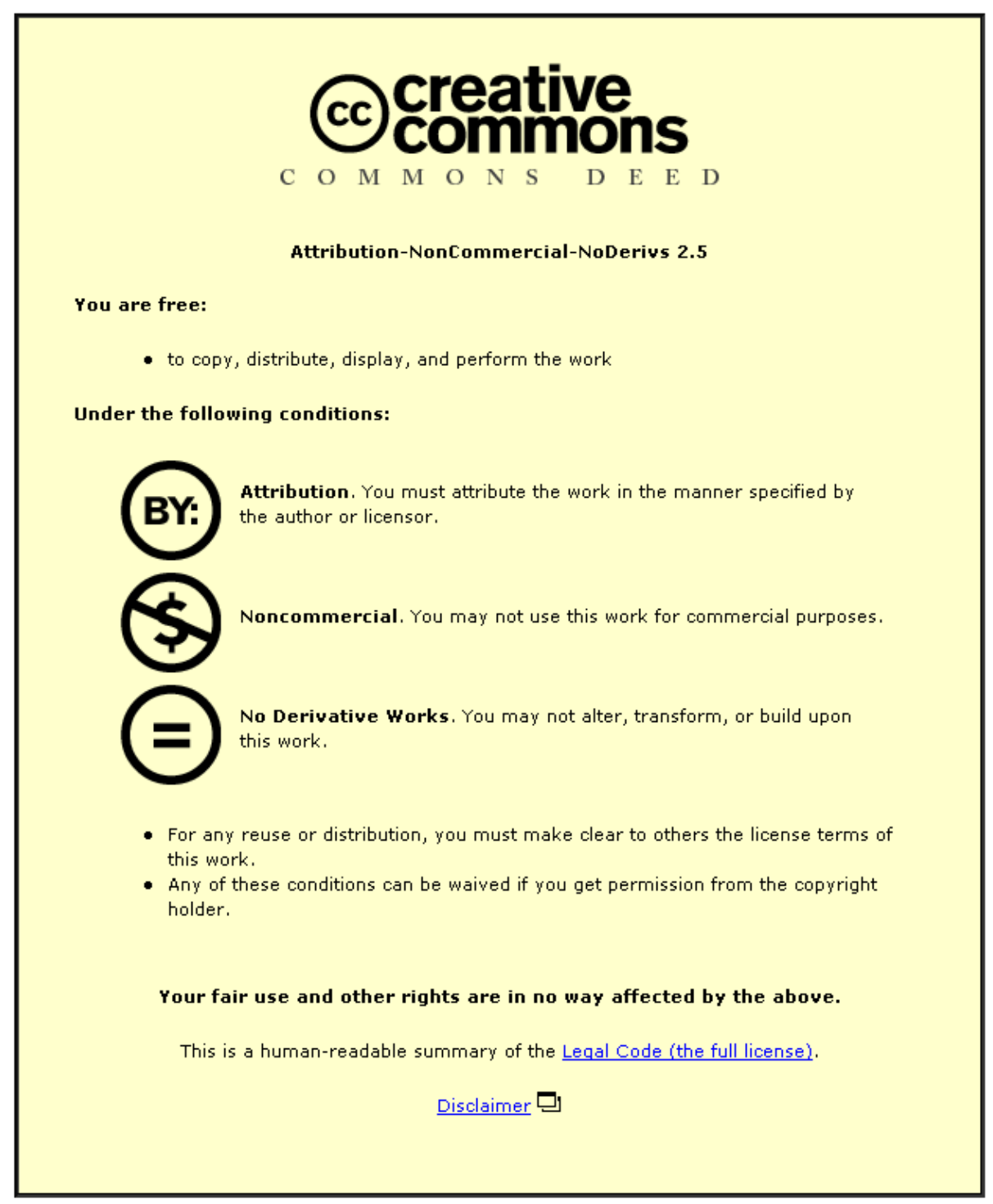

For the full text of this licence, please go to: http://creativecommons.org/licenses/by-nc-nd/2.5/ 

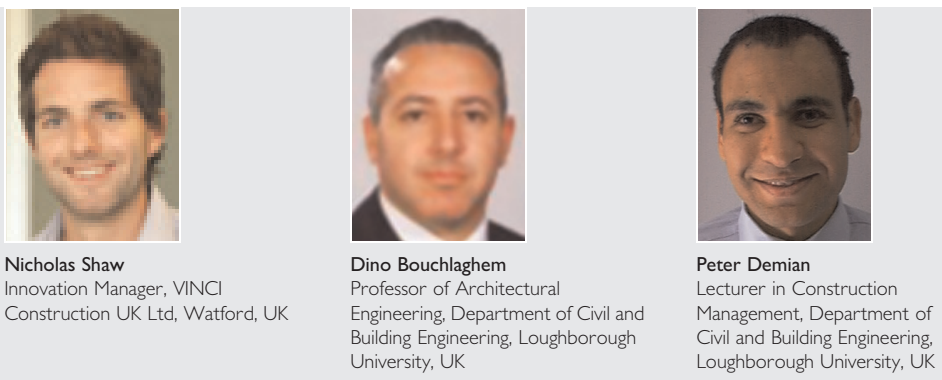

\section{Key influences of innovation magnitude and mode}

\section{N. Shaw BSc(Hons), D. Bouchlaghem DipArch, PhD and P. Demian MA, MEng, MSc, PhD, MASCE}

There is plenty of recognition of the need for more innovation in the construction sector. Increasing levels of competition, rapid technological and regulatory change, the current economic climate and environmental concern all accentuate this requirement. In response, many construction firms are seeking ways to manage innovation more actively and conscientiously in order to remain competitive. However, there is little practical guidance for construction professionals on how to make innovation flourish in their teams. Those who aspire to improve the management of innovation will need to understand how innovation happens, what are the driving forces and how can they be influenced. This paper reports on an empirical investigation that was undertaken to explore some of these questions, specifically the role of organisational climate, customers, risk and complexity on the levels of innovation in teams and the various modes of innovation that prevail - with the aim of providing practitioners with clearer guidance on where efforts should be focused. The findings suggest that there are a limited number of fundamental factors that significantly influence innovation magnitude and mode. For industry professionals it is hoped that this stimulates debate and assists in establishing a much needed foundation for improved innovation management in construction.

\section{INTRODUCTION}

The need for change and improvement in the construction industry has been well documented (Egan, 1998; Fairclough, 2002). Indeed, it is argued that the industry is facing some of its greatest challenges yet, including increased competition, radical technological change, increasing product complexity, tougher regulations and the need to minimise environmental impact, and as a consequence this need for change has never been greater.

It is through innovation, which can be defined as 'the successful exploitation of an idea' (DTI, 2003), that construction firms will be able to create solutions in response to many of these challenges. As a result, innovation is becoming an ever more essential ingredient for winning work and increasing profitability in the sector (Seaden et al., 2003; Tatum, 1991), with more and more construction firms recognising the need to manage innovation in a more strategic and conscientious manner (Hartmann, 2005; Wamuziri and Madan, 2009).
The premise of this paper is that in order for construction firms to achieve improvement in the management of innovation, they will first need to establish a firmer understanding of how innovation is realised in practice. In other words, organisations need to be clear about what they are trying to manage; as the rest of this paper will attest, innovation comes in many different forms.

However, understanding the modes of innovation is not enough. Construction firms will also benefit from gaining a better understanding of the driving forces behind these events. Although there has been a recent spate of research into the driving and restraining forces for innovation, little empirical work has been carried out in construction firms to validate the theory.

This paper presents an overview of a recent research project, conducted and led by a large UK construction, facilities and associated services firm, which aimed to empirically investigate how innovation is realised in practice and what factors significantly influence these activities. It is hoped that the findings from this research will help to inform and reinforce future strategic decisions relating to the management of innovation and its capitalisation in construction firms.

\section{RESEARCH METHODOLOGY}

The research project was divided into five stages, where the output from each stage was required for the subsequent stage (Figure 1).

A variety of recognised research methods were implemented across the stages. The key activities are listed here.

(a) Extensive literature review - to establish current 'state of the art' construction innovation management, including theory on the driving and restraining forces of innovation. These findings were used to inform the development of the input model.

(b) Input model - to visually represent the key variables of innovation magnitude and mode and their hypothesised causal relationships, as identified in the literature review. The input model was also used to guide the survey content and structure.

(c) Survey design and field study - designed to collect the necessary data to validate the input model. Each factor included in the input model was measured in the survey, 


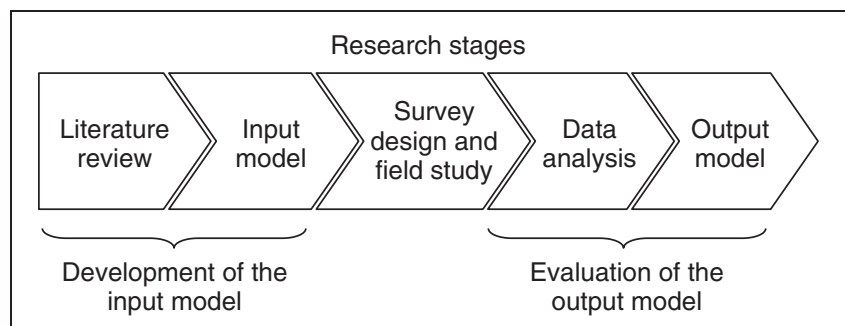

Figure I. Research project stages

using multiple items and previously validated scales from the literature where possible. The survey was administered in June 2009 and the sample included 93 people in 12 autonomous teams working in various managerial and technical roles. A total of 69 complete and usable responses were received (achieving a very satisfactory response rate of 74\%) with appropriate representation from 11 teams.

(d) Data analysis - path analysis was used to analyse the survey data to provide estimates of the magnitude and significance of hypothesised causal connections between the sets of variables included in the input model. The product of this analysis is an output model.

(e) Output model - a revision of the input model which shows what was actually observed in the data, based on established statistical methods. This output model was used to assess which variables had the greatest influence on innovation magnitude and mode.

\section{DEVELOPMENT OF THE INPUT MODEL}

This section of the paper presents an overview of the theory and draws out the critical factors for inclusion in a theoretical input model of innovation at the project/team level. The input model attempts to describe the variables that influence team innovation performance and modes of innovation, and shows the hypothesised causative relationships between these based on the literature (Figure 2). The rest of this section explores each variable in turn, including a brief review of the supporting literature.

\section{I. Innovation mode}

How does innovation happen in construction? Without a clear understanding of this, how can firms improve their management of innovation?

The construction industry is often criticised for resisting change and is frequently characterised as one that fails to innovate in comparison with other sectors. Traditional measures of innovation, such as investment in formal research and development (R\&D) and number of patents awarded, only lend support to such criticism. Indeed, during 2008 the construction sector investment in R\&D as a percentage of sales

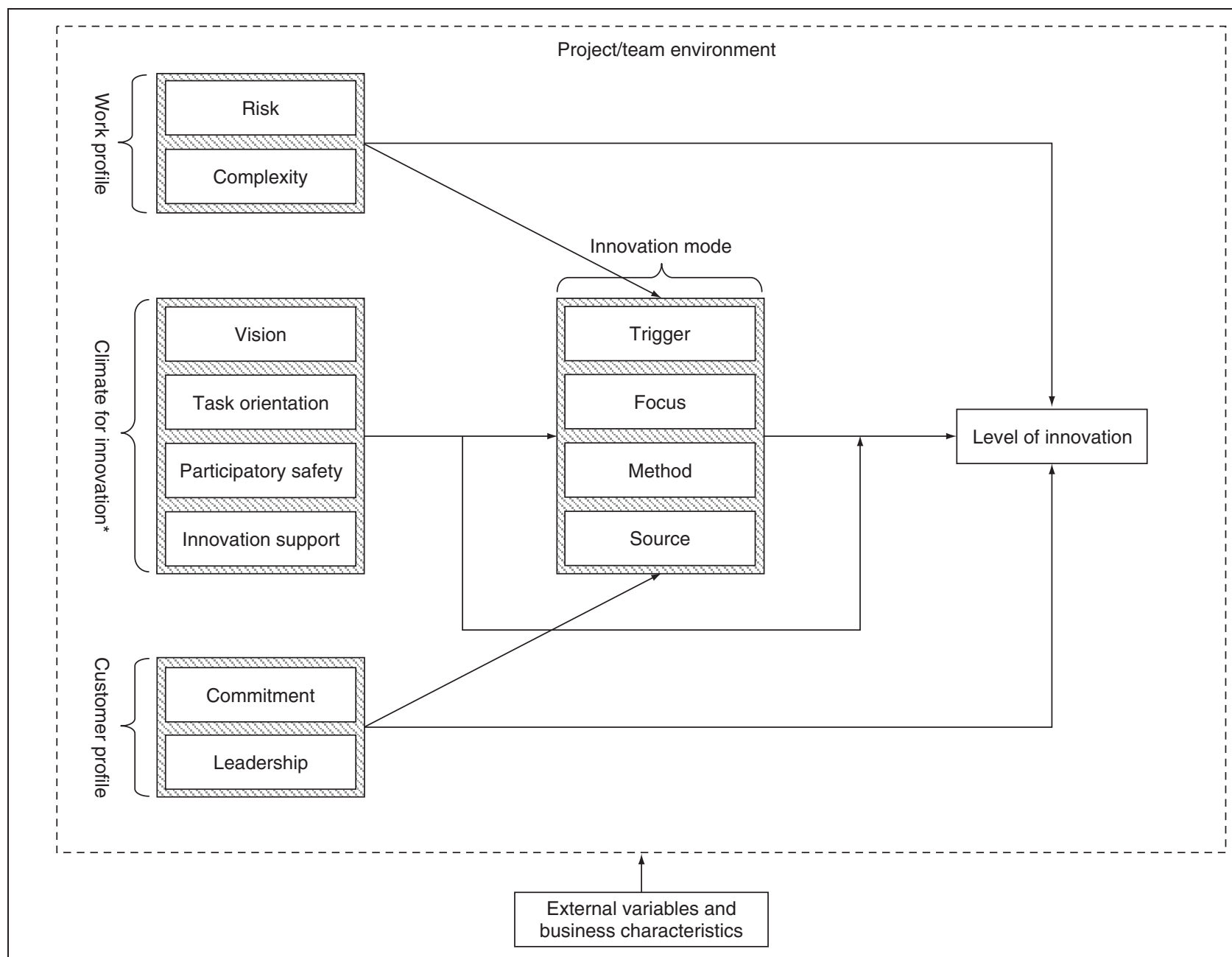

Figure 2. Input model of team innovation: "Team Climate Inventory (Anderson and West, 1998) 
was a mere $0 \cdot 4 \%$, which is markedly less in comparison with other industry sectors (BERR, 2008).

However, are these traditional measures of innovation representative of how innovation is realised in the sector? Recent work by the National Endowment for Science, Technology and the Arts (NESTA) suggests that these traditional measures are based on a formal RED 'pipeline' model of innovation that is increasingly less relevant, and that they fail to measure the form of innovation that dominates many sectors, including construction (NESTA, 2007).

To increase understanding of innovation it is essential to acknowledge that learning, research and development is not solely restricted to the RED department in construction firms (Gann and Salter, 2000). Innovation in construction often takes place locally, at the micro-level on projects, and is very much an intrinsic part of the day-to-day problem solving and 'learning by doing' nature of the sector, where research is conducted and expertise is developed during the course of a project (Gann and Salter, 2000).

Insightful work by Winch (1998) highlights the important role that this 'informal' mode of innovation plays in the construction firm, and asserts that solutions resulting from problem-solving and learning by doing type activities on projects must be captured, learned, diffused and applied on future projects before it can be considered as innovation. Most top managers in construction indicate that innovations are usually developed in this way (Nam and Tatum, 1997).

Other researchers have emphasised the need to distinguish between this mode of informal innovation, which is often incremental in its nature, and the concept of general improvement. The general consensus is that innovation must involve a creative, inventive or exploratory step and result in a tangible benefit in the firm concerned, whereas general improvement may not necessary incorporate invention or result in a firm wide impact on performance (NESTA, 2007).

Of course, innovation also occurs at a more strategic level in construction firms. One such route is via formal RED activities, but R\&D intensity figures for the industry would suggest that this is not a favoured method of innovating in the sector (BERR, 2008). Other activities at a more strategic level include decisions concerning the adoption and implementation of new technologies, products, materials and processes sourced externally from the firm (Winch, 1998).

So what are the typical characteristics that can be used to define these 'formal' and 'informal' modes of innovation? Interviews with industry practitioners indicate that formal innovation is more likely to be triggered proactively, in anticipation of a future opportunity or challenge, and has a longer-term focus in comparison with informal, learning-bydoing modes of innovation (Shaw and Bouchlaghem, 2008). It is also argued that formal innovation is less likely to be bound by traditional project constraints (Hartmann, 2005; Shaw and Bouchlaghem, 2008) but is conducted 'off-line' from daily operations - often as a project in its own right. As a result, this mode of innovation is commonly subjected to more rigid processes and controls, similar to new product development processes used in the manufacturing industries. The longer timescales often involved provide greater opportunity for a more outward focus and often enable collaboration with customers, suppliers and the scientific community.

Conversely, it is proposed that informal innovation is much more likely to be a reactive event, triggered in response to solve a problem or seize an opportunity. This form of innovation is typically practitioner led, and often occurs in the project environment where it will be constrained and pressured by project time frames and budgets (Hartmann, 2005; Shaw and Bouchlaghem, 2008). To successfully exploit an idea in this type of environment requires agility and autonomy, working with the people and expertise at hand rather than seeking additional internal or external support.

From this it is reasonable to distil at least four attributes that can be used to help differentiate formal and informal innovation: the 'trigger' event (reactive versus proactive), the 'focus' of the innovation (short-term need versus long-term opportunity), the 'method' of development (flexible, ad hoc and bespoke processes versus rigid, structured and established processes), and the 'source' (internally centred versus externally centred activity).

Surely to achieve improved management of innovation it is essential to understand these different modes of innovation, as contingency theory would attest that they need to be managed in different ways (Winch, 1998). In order to explore the relationships between innovation mode and innovation magnitude, the four attributes highlighted above were included in the input model (Figure 2).

In addition to establishing a better understanding of the modes of innovation in construction, it is also essential to ascertain the driving and retaining forces that influence levels of innovation. Current research on the topic reveals convergent themes, largely centred on the impact of organisational climate for innovation and the role of the construction customer.

3.1.1. Climate for innovation. The role of climate and its influence on innovation performance continues to receive considerable attention from researchers and practitioners alike. However, the notion of climate is complex and frequently misunderstood. Therefore, it is perhaps useful to first provide a definition and briefly discuss related difficulties.

\subsubsection{Definition of climate. There are conflicting views} regarding the notion of climate (Baer and Frese, 2003) since there are both theoretical and disciplinary differences in what climate represents (Patterson et al., 2005). For the purposes of this research the predominant approach was selected, which conceptualises climate as employees' shared perceptions of organisational policies, practices and procedures (Patterson et al., 2005). The principle is that if people in an organisation share similar perceptions of a psychological climate dimension, it is legitimate to aggregate these individual perceptions into a composite indicator of climate (Baer and Frese, 2003). This leads to the next complexity - what unit of 
analysis should be selected to represent a collection of shared perceptions?

3.1.3. Level of analysis. Researchers have studied climate at different levels of analysis, such as proximal work groups, departments or organisations (Patterson et al., 2005). This is commonly achieved by aggregating individual scores from psychometric questionnaires to the desired level, using the mean average to represent the climate at that level. The rationale behind this is that the diversity and sheer size of many organisations warrant a more micro-analytical examination of shared perceptions at the level of the work group, team or sub-unit (Anderson and West, 1998). Indeed, there are real concerns about the extent to which agreement of climate perceptions can be demonstrated across entire organisations.

This assertion seems particularly logical when considered in the context of the typical construction firm, which consists of multiple, semi-autonomous, temporary and fragmented teams which, when considered in their widest sense, include team members from outside the boundary of the firm. Logic suggests that it is unreasonable to expect consistent and shared perceptions across an organisation of such a complex and dynamic nature. Therefore in the present research, climate was investigated at the proximal team level, which has been eloquently defined by Anderson and West (1998, p. 236) as "the permanent or semi-permanent team to which individuals are assigned, whom they identify with, and whom they interact with regularly in order to perform work related tasks'.

3.1.4. Climate dimensions. Many investigations in the field of organisational psychology attest that it is meaningless to apply the concept of climate without adopting a facet-specific approach, where climate has a focus on a dimension of interest, which is often dependent on the purpose of the investigation (Anderson and West, 1998; Patterson et al., 2005). As a result a plethora of measures for various dimensions of climate have been developed, many of which are concerned with innovation at various levels of analysis.

One such measure which has demonstrated robust reliability and validity is the short version of Anderson and West's Team Climate Inventory (TCI) (Anderson and West, 1998). Their work has identified four factors that are highly influential in an organisational climate for innovation. These factors are summarised here.

(a) Vision - a concern with providing clear, high order, organisational goals and a motivational force at work, thereby reinforcing team member understanding and commitment to objectives (Anderson and West, 1998). Previous research in construction firms has also suggested that innovation needs to become a shared value within a firm for it to flourish (Hartmann, 2005).

(b) Task orientation - a shared concern with excellence in task performance, characterised by overtly reviewing and reflecting upon objectives, strategies and work processes, in order to adapt to the wider environment (Anderson and West, 1998; De Dreu, 2002). Research in the construction sector has provided evidence that worker autonomy and flexible role definitions have a significant influence on innovation performance (Winch, 2000).

(c) Participatory safety - an employee's sense of being able to express one's self without fear of negative consequences and where involvement in decision making is encouraged and reinforced (Anderson and West, 1998).

(d) Support for innovation - the extent of articulated and enacted encouragement, expectation, approval and practical support of attempts to successfully exploit ideas and deliver innovation in the work environment (Anderson and West, 1998). Perceived support for innovation has been consistently shown to be significantly related to levels of innovation in construction teams (Dulaimi et al., 2005).

However, it should be recognised that there are also a number of factors external to the typical construction firm that are widely considered to influence both innovation magnitude and mode, in particular the role of the customer.

\subsection{Customer profile}

The importance of the customer role in innovation is a theme echoed across industries (Winch, 1998). In the manufacturing industry this role is generally passive but held in high regard, where innovation is supported by the capture, interpretation and validation of both expressed and latent customer needs for input into new product development processes (Cristiano et al., 2000). Customers of the construction industry play a much more active and integrated role throughout the project life cycle and are considered to be highly influential in the delivery of innovation (Blayse and Manley, 2004; Nam and Tatum, 1997).

Conceptual and empirical investigations into the role of the customer in construction innovation have drawn out a number of consistent attributes that are supportive of an environment that fosters innovation (Blayse and Manley, 2004).

Sustained and long-term relationships between customers, contractors and designers are known to be conducive for innovation (Nam and Tatum, 1997). These types of relationships are often underpinned by a culture of trust, commitment and understanding between parties (Wamuziri and Madan, 2009), which is related to the concepts of climates for psychological safety, vision, task orientation and support for innovation discussed earlier in this paper.

Frequent interaction and engagement with customers is beneficial for the generation of innovation in a number of ways. Regular contact can decrease idea approval times, provides more opportunity to discuss needs and explore alternatives, and it can provide a good basis to reinforce relationships.

There is also much evidence that customers with a broad experience and familiarity with the construction industry often have a positive impact on innovation and its diffusion (Hartmann, 2005; Nam and Tatum, 1997). Customers often gain this experience through engagement in repeat construction activity and from this develop increased technical knowledge and awareness of the specific challenges embedded in the industry thereby reinforcing the role of relationships and interaction. 
Increased technical awareness is closely related to active participation in projects, better understanding of technical issues, and the ability to overcome the uncertainty of construction innovation, leading to timely approval and support of new ideas (Nam and Tatum, 1997).

Customers who not only accept innovation but expect it, are often more successful at stimulating innovation (Barlow, 2000). Once again, strong parallels exist between customer demand patterns, the level of technical competency, construction experience and the strength of relationship. Perhaps more experienced customers attach more value to long-term relationships, which in turn increases technical competency, ambition and expectations.

\subsection{Work profile}

Perceptions of risk, whether at the industry, company or project level, can exert a significant influence on both the magnitude and management of innovation (Tidd, 2001). This is extremely topical, given the challenges faced in the current market conditions. The notion of complexity is also considered to play an influential role, where complexity is considered to be a function of the number of technologies and their interactions (Kivimäki and Elovaino, 1999). Although risk and complexity are not necessarily highly correlated, greater levels of complexity often lead to increased risk as the number of technologies and interactions grow. Precisely how these contingencies independently or collectively affect the degree, type and management of innovation is less clear and more empirical research has been called for.

In addition to the factors discussed above, the literature review revealed a number of other explanatory variables for innovation performance in the sector, but due to the need to control the size and complexity of the input model of innovation to ensure its appropriateness for analysis it was decided to focus only on these dominant themes at this stage.

\section{SURVEY DESIGN AND FIELD STUDY}

The input model and the supporting literature were used to guide the design of the 43-item field study survey. For each factor identified in the input model the survey had a corresponding set of items designed to measure it. Wherever possible, previously validated scales and multiple items were used in the survey to improve reliability and validity. All composite measures included in the model were checked for reliability and provided a Cronbach's alpha $>0 \cdot 70$, a commonly adopted and acceptable level for internal reliability (Hair et al., 2005).

The survey was administered in June 2009 and the sample included 93 randomly selected people from 12 autonomous teams working in various managerial and technical roles. A total of 69 complete and usable responses were received (achieving a very satisfactory response rate of 74\%) with appropriate representation from 11 teams.

\section{I. Survey measures}

Risk and complexity were measured using single items by asking respondents to rate the perceived risk and complexity of their project on a scale of 1 (very low) to 5 (very high), following a similar format to Dulaimi et al. (2005).
A slightly modified version of Anderson and West's short version of the Team Climate Inventory (TCI) was used to measure the perceived climate for innovation (Anderson and West, 1998). The TCI (short version) includes four factors: vision (four items), task orientation (four items), participatory safety (five items) and support for innovation (four items). All items were measured on a five-point scale.

Customer profile was assessed using seven items on a fivepoint scale. The authors developed seven items based on the literature to provide a rounded definition of the role and influence of the customer on innovation levels including: attitude to risk, willingness to sponsor new ideas, construction experience, technical competence, relationship strength, frequency of interaction, and levels of expectation.

Innovation mode was measured using four items on a fourpoint scale to capture the typical trigger of innovation (proactive versus reactive), the focus of efforts (long- versus short-term), the method of realisation (formal versus informal) and the source (internal versus external to the company).

Level of innovation was measured using a slight modification of the items adopted by Dulaimi et al. (2005). The construct reflects the degree of perceived ability to innovate in the workplace, including the generation and exploitation of new ideas which led to the introduction of improved processes, technologies and materials.

\section{ANALYSIS OF RESULTS}

\section{I. Factor analysis}

In order to examine any underlying dimensions and to determine whether the data could be reduced (by combining variables into summated scales) the seven items that made up the customer profile construct were subjected to principal component analysis (PCA). The Kaiser-Meyer-Olkin (KMO) measure of sampling adequacy was 0.551 , exceeding the minimum acceptable value of 0.5 (Hair et al., 2005), and the Bartlett's test of sphericity was significant ( $p=0 \cdot 000$ ), indicating suitability of the data for factor analysis. The ratio of sample size to number of variables was almost 10:1, where the recommended minimum ratio is commonly considered to be 5:1 (Hair et al., 2005), lending further support to the factor analysis.

The factor analysis of the seven customer profile variables produced a three-factor solution that explained 66.89\% of the variation. All three factors had eigenvalues greater than 1 and interpretation of the scree plot also suggested that three factors should be extracted. Only items that loaded on a single factor with loadings greater than 0.65 were retained, based on good practice guidelines defined by the sample size (Hair et al., 2005). Of the original items two failed to load substantially on any of the factors and were subsequently removed from the analysis. The factors were interpreted in the following manner.

(a) Factor I, which accounted for $26 \cdot 56 \%$ of the variance, comprised two items from the original construct which were concerned with the strength and quality of relationship with the customer and the frequency of interaction experienced. The factor was considered 


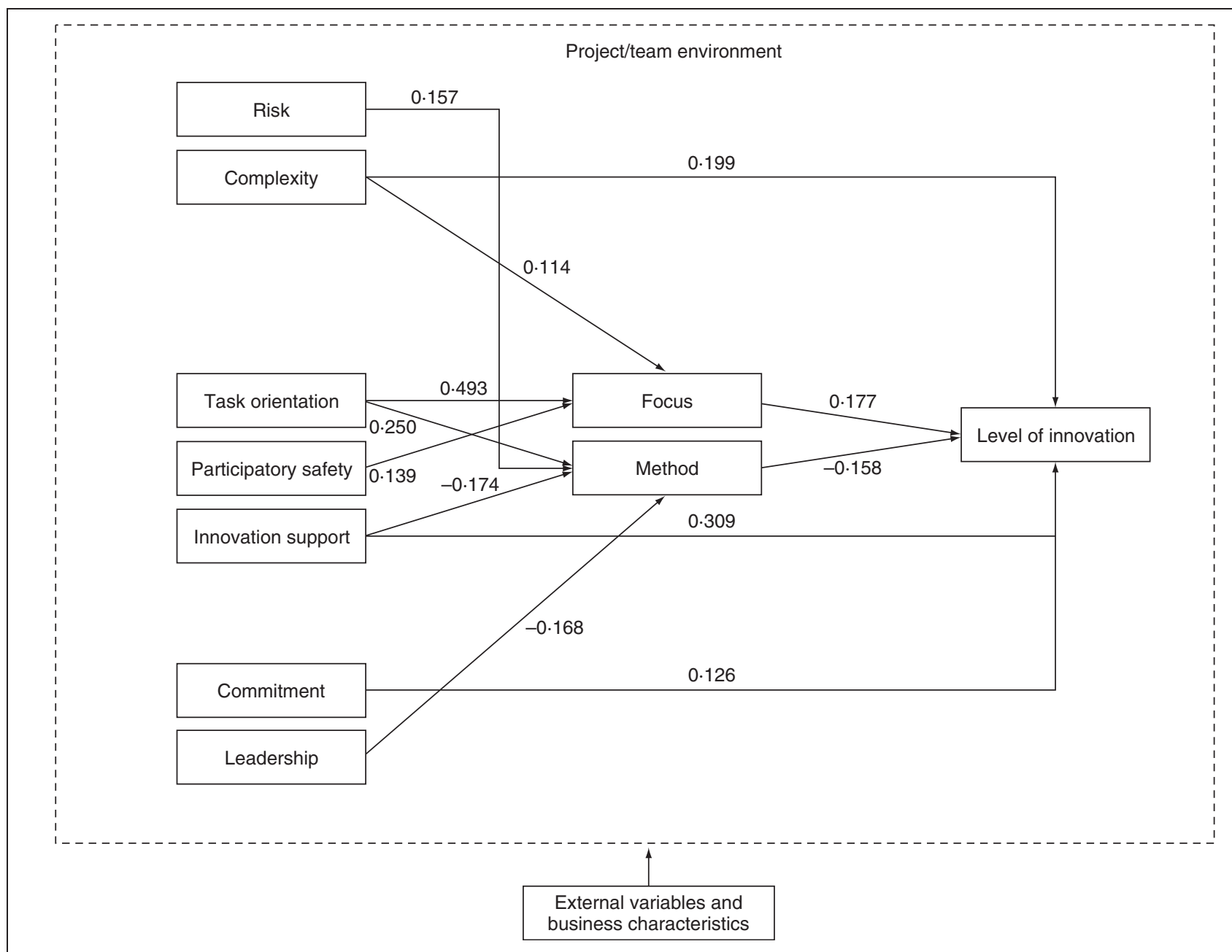

Figure 3. Output model of team innovation: note that path coefficients $<0.1$ have been omitted

conceptually clear and was named commitment.

Cronbach's alpha for this factor as a composite scale on the sample was 0.72 indicating acceptable levels of homogeneity and reliability.

(b) Factor II accounted for $20 \cdot 25 \%$ of the variance, but included only a single item concerned with customer attitude towards risk. Items relating to customer technical competence and willingness to sponsor new ideas also loaded on the factor $(0.621$ and 0.543 , respectively), but did not meet the required level of loading $(>0 \cdot 65)$. Cronbach's alpha for this factor was unsatisfactory and was therefore not included in the path analysis.

(c) Factor III accounted for $20 \cdot 08 \%$ of the variance and comprised two items, the first representing the customer's actions towards setting tough and ambitious targets and the second concerning the level of experience in construction. The factor demonstrates the role of the customer in terms of 'pulling' innovation and understanding the nature and complexities of the industry, and was therefore named leadership. Cronbach's alpha was $0 \cdot 75$.

\subsection{Path analysis}

The data were checked for normality and absence of multicollinearity. In addition to examining the normal probability plot for each variable, tests of normality based on skewness and kurtosis values (Hair et al., 2005) revealed no statistically significant deviations. All of the factors in the model were represented by either single variables or summed scaled measures, resulting in a single indicator per factor. The recommended ratio of sample size to number of variables should be between 5:1 and 10:1 (Hair et al., 2005); in this study the ratio was $1: 5 \cdot 31$ and therefore falls within acceptable limits.

The results from the survey were evaluated using path analysis, a simple extension of hierarchical multiple regression (Pedhazur, 1982). This technique aims to provide estimates of the magnitude and significance of hypothesised causal relationships between sets of variables in the input model. As presented earlier in this paper, the input model (Figure 2) depicts the variables and predicted causal relationships identified in the literature. Path analysis can then be applied to compute a path coefficient for each connection between variables to provide a steer on which casual hypotheses from the input model are better supported by the data. This is achieved by conducting multiple regression analysis on each endogenous variable in the model, predicting the dependent variable from all directly related explanatory variables. The standardised beta weights from these multiple regressions are the path coefficients used in the path analysis output diagram (Figure 3). 
The path coefficients can be interpreted in exactly the same manner as betas derived from multiple regression analysis. For the purposes of interpretation, the squared value of a path coefficient provides the proportion of the dependent variable's variance that is caused by the explanatory variable (i.e. explanatory variable $X$ describes $n \%$ variation in dependent variable $Y$ ). Path coefficients from extraneous variables and those with an absolute value less than $0 \cdot 1$ have been omitted for visual clarity.

\section{DISCUSSION}

This study has provided a unique insight into the relationships and significance of a number of variables and their influence on innovation magnitude and mode in the context of a construction firm. In particular, the study has highlighted the complexity and role of innovation mode as a mediating factor for innovation performance in the construction context, which has received limited attention in previous research efforts.

In this study innovation was typically seen as a short-term, internal and reactive activity, which was dealt with on a more informal, ad hoc basis - interwoven into the day-to-day problem-solving nature typical of the construction sector. There were also examples of teams and individuals adopting a longer-term, proactive and formal approach towards the exploitation of innovation, although such approaches were observed less frequently across the sample. This provides empirical evidence for the existence of different modes of innovation in construction beyond the more formal RAD and 'pipe-line' management approaches. Furthermore, the findings suggest that the mode of innovation itself influences perceived levels of innovation, with teams and individuals adopting a longer-term focus combined with a more informal approach towards the exploitation of innovation reporting greater innovation success in the workplace.

Achieving a long-term focus for innovation is a challenge in the construction context, since most innovation activities are bound by individual project time frames and budgets. Professionals concerned with the management of innovation will need to find ways to encourage a longer-term view, one that is frequently reviewed and communicated across teams, that stretches beyond the needs and limitations of an individual project. Part of the answer might be through the provision of an organisational climate that encourages both task orientation and participatory safety, both shown in this study to significantly influence innovation focus.

The results showed that organisational support for innovation was the strongest predictor of innovation and was the only climate dimension that directly and significantly influenced levels of innovation. Where teams perceived greater organisational support for innovation they were found to be more likely to proactively initiate activities with the goal of achieving innovation. These proactive events, by their nature, allow for longer time scales and therefore increase the likelihood of successful exploitation, as previously discussed.

In practical terms organisational support for innovation should form a priority for firms seeking to improve their innovation outlook, but the findings suggest that managers need to exercise caution and provide balanced solutions that support both formal and informal modes of innovation. Failure to support informal methods of innovating was found to have a negative impact on perceived levels of innovation in the study. The majority of existing guidance for the management of innovation focuses on formal methods of delivery, much of it inspired from practices that are well established in the manufacturing sector, and more guidance for the support of informal modes is called for.

In contrast to previous research (Dulaimi et al., 2005) it was found that higher levels of perceived complexity were moderately associated with increased levels of innovation. It is anticipated that the increased number of technologies and interactions present in more complex environments provide more opportunities for the development and application of new ideas, technologies and processes. On a more general note, it seems that employees of technical businesses tend to thrive on complex challenges - particularly when the problem to solve has been carefully defined and the associated risk is managed. Managers and strategy makers might wish to seek to benefit from this attribute, and purposefully select, refine, communicate and engage the workforce in 'off-line' collaborative problem-solving projects for the 'big issues', as defined by the business and its customers. Risk was found to have an influence on the method of innovation, encouraging a more formal and structured approach when perceived risks were higher, which is in keeping with logical reasoning.

The level of customer commitment, measured in terms of strength of relationship and frequency of interaction, had a direct impact on team innovation levels. Trust, transparency and understanding between parties are frequently cited as key enablers for innovation in construction literature and the data support these assertions. Surprisingly, the variables associated with customer experience and demand for innovation did not reveal a significant relationship with the level of innovation, despite their reference in the literature (Blayse and Manley, 2004). These variables did however influence the method of innovation, where customers who articulated a greater demand for innovation and had previous experience as construction customers encouraged teams to adopt a more formal approach to innovation. It is thought that this is perhaps a result of teams attempting to demonstrate and measure innovative activities to meet the expectations of more demanding customers.

\section{CONCLUSIONS}

Construction firms have recognised the need to manage innovation more actively and conscientiously to remain competitive in today's dynamic and challenging business environment. This is not a task to be underestimated. Innovation in construction is complex, multi-faceted and sensitive to underlying cultural and climatic forces. Such forces are notoriously difficult to manage in construction organisations, where teams are often fragmented and of a temporary nature. A fundamental step towards the true achievement of improved management of innovation requires a better understanding of the dynamics of innovation at the firm and project level, equipping managers and strategy makers with the knowledge required to support innovation from grass roots through to the boardroom. 
This paper has reported on an empirical investigation of the role of organisational climate, customer profile, risk and uncertainty on levels of innovation in proximal teams and the various modes of innovation that prevailed in a major UK construction, facilities and associated services firm. The resultant model reveals both the magnitude and relationships between the variables selected for investigation, contributing to current knowledge of the hidden dynamics of innovation in the construction firm. It is hoped that this insight will provide some important clues for those who seek to improve the innovation outlook of their organisations.

There is, however, still much to learn and more research is required. Our future work will focus on further developing and refining the model, addressing the need for more rigorous and extensive analysis of the influencing factors of innovation magnitude and mode, and providing practical guidance for managers and strategy makers in construction who have the ambition of making innovation thrive in their organisations.

\section{I. Limitations}

As with most forms of statistical analysis there are a number of limitations that need to be expressed. The data collection relied on responses based on perceptions rather than actual practices and as such the self-reporting may have potentially exposed results to bias, although established practices to mediate for this were adopted. The size of the sample was small $(n=69)$ but sufficient to meet the aims of this research. As with any study using a small sample, caution should be exercised when generalising the results but the findings do provide useful directions for future work. It is recommended from this study that future research is conducted in different project settings for cross-comparisons and further development of the model in order to draw more robust conclusions.

The application of path analysis to evaluate relationships among variables has become a popular technique. Within a given path diagram, path analysis can tell us which are the most important and significant paths in a given diagram, and this may have implications for the plausibility of any causal hypotheses, but path analysis cannot tell us which of two distinct path diagrams is to be preferred or establish the direction of causality between correlated variables (Everitt and Dunn, 1991).

\section{REFERENCES}

Anderson N and West M (1998) Measuring climate for work group innovation: development and validation of the team climate inventory. Journal of Organizational Behaviour 19(3): 235-258.

Baer B and Frese M (2003) Innovation is not enough: climates for initiative and psychological safety, process innovations, and firm performance. Journal of Organizational Behaviour 24(1): 45-68.

Barlow J (2000) Innovation and learning in complex offshore construction projects. Research Policy 29(7): 973-989.

BERR (Department of Business Enterprise and Regulatory Reform) (2008) The 2008 RAD Scoreboard, Company Data. BERR, London, UK.

Blayse A and Manley K (2004) Key influences on construction innovation. Construction Innovation 4(3): 143-154.
Cristiano J, Liker J and White C (2000) Customer-driven product development through quality function deployment in the US and Japan. Journal of Product Innovation Management 17(4): 286-308.

De Dreu C (2002) Team innovation and team effectiveness: the importance of minority dissent and reflexivity. European Journal of Work and Organizational Psychology 11(3): 285-298.

DTI (Department of Trade and Industry) (2003) Innovation Report, Competing in the Global Economy: The Innovation Challenge. DTI, London, UK.

Dulaimi M, Nepal M and Park M (2005) A hierarchical structural model of assessing innovation and project performance. Construction Management and Economics 23(6): 565-577.

Egan J (1998) Rethinking Construction: The Report of the Construction Task Force. DETR, London, UK.

Everitt B and Dunn G (1991) Applied Multivariate Data Analysis, 2nd edn. Edward Arnold, London.

Fairclough J (2002) Innovation in the Construction Industry - a Review of Government R\&D Policies and Practices. DTI, London, UK.

Gann D and Salter A (2000) Innovation in project-based, service-enhanced firms: the construction of complex products and systems. Research Policy 29(7): 955-972.

Hair J, Black W, Babin B, Anderson R and Tatham R (2005) Multivariate Data Analysis, 6th edn. Prentice Hall, Englewood Cliffs, NJ, USA.

Hartmann A (2005) The context of innovation management in construction firms. Construction Management and Economics 24(6): 567-578.

Kivimäki K and Elovaino K (1999) A short version of the Team Climate Inventory: development and psychometric properties. Journal of Occupational and Organizational Psychology 72(2): 241-246.

Nam C and Tatum C (1997) Leaders and champions for construction innovation. Construction Management and Economics 15(3): 259-270.

NESTA (National Endowment for Science, Technology and the Arts) (2007) Hidden Innovation - How Innovation Happens in Six 'Low Innovation Sectors'. NESTA, London, UK.

Patterson G, West M, Shackleton V et al. (2005) Validating the organizational climate measure: links to managerial practices, productivity and innovation. Journal of Organizational Behaviour 26(4): 379-408.

Pedhazur E (1982) Multiple Regression in Behaviour Research, 2nd edn. Holt, Rhinehart and Winston, New York, USA.

Seaden G, Guolla M, Doutriaux J and Nash J (2003) Strategic decisions and innovation in construction firms. Construction Management and Economics 21(6): 603-612.

Shaw N and Bouchlaghem N (2008) Challenges, opportunities and recommendations for collaborative product development in construction - a UK Construction Strategic Alliance Partnership perspective. In Proceedings of the Joint CIB W096 and CIB TG49 Conference (Melhado S (ed.)). CIB, São Paulo, Brazil.

Tatum C (1991) Incentives for technological innovation in construction. In Proceedings of a Conference on Preparing for Construction in the 21 st Century (Chang L (ed.)). ASCE, New York, pp. 447-452. 
Tidd J (2001) Innovation management in context: environment, organization and performance. International Journal of Management Review 3(3): 169-183.

Wamuziri S and Madan S (2009) Improvement and innovation through collaborative partnerships. Proceedings of the ICE Management, Procurement and Law 162(1): 17-27.
Winch G (1998) Zephyrs of creative destruction: understanding the management of innovation in construction. Building Research and Information 26(4): 268-279.

Winch G (2000) Innovativeness in British and French construction: the evidence from Transmanche-Link. Construction Management and Economics 18(7): 807-817.

\section{What do you think?}

To discuss this paper, please email up to 500 words to the editor at journals@ice.org.uk. Your contribution will be forwarded to the author(s) for a reply and, if considered appropriate by the editorial panel, will be published as a discussion in a future issue of the journal.

Proceedings journals rely entirely on contributions sent in by civil engineering professionals, academics and students. Papers should be 2000-5000 words long (briefing papers should be 1000-2000 words long), with adequate illustrations and references. You can submit your paper online via www.icevirtuallibrary.com/content/journals, where you will also find detailed author guidelines. 